\title{
ОЦЕНКА ПОТЕНЦИАЛА ЭКСПОРТА УСЛУГ РЕСПУБЛИКИ БЕЛАРУСЬ НА РЫНКЕ КИТАЙСКОЙ НАРОДНОЙ РЕСПУБЛИКИ
}

\author{
И.Л. Телеш, И.В. Баханцева, Р.А. Русаков"
}

Дана оценка среднесрочного потенциала роста экспорта услуг Республики Беларусь в Китайскую Народную Республику. Рассмотрены различные подходы к выявлению его перспектив и динамика за 20152019 гг. Анализ основан на существующей методологической базе, в частности на разработках Международного торгового центра (ITC). Дополнительно проведена оценка потенциала экспорта в случае либерализации торговых отношений между сторонами и снижения уровня нетарифных барьеров в торговле услугами.

Ключевые слова: внешняя торговля, экспорт услуг, экспортный потенциал, торговые барьеры.

JEL-классификация: F14, F17.

DOI: $10.46782 / 1818-4510-2021-1-118-129$

Материал поступил 25.02.2021 2.

На современном этапе развития мирового хозяйства сфера услуг является одним из основных источников роста производительности экономики страны, играя значимую роль на всех стадиях процесса производства. Для Республики Беларусь, малой открытой экономики с дефицитом топливно-энергетических и сырьевых ресурсов, торговля услугами остается важной составляющей, обеспечивающей положительный вклад в баланс внешней торговли и в формирование ВВП. В этой связи оценка перспектив роста внешней торговли услугами страны остается актуальной проблемой в экономических исследованиях.

Международный оборот различных видов услуг характеризуется рядом особенностей. В отличие от внешней торговли товарами, экспорт и импорт услуг не имеют натурального выражения, в связи с чем отличаются большей сложностью оценки и прогнозирования.

\section{Методические подходы к оченке әкспортного потенциала отдельных видов услуг на иелевом рынке}

Следует констатировать, что на сегодняшний день научным сообществом не выделена единая методология оценки экспортного потенциала услуг на целевом рынке, а существующие подходы в достаточной мере не проработаны. В большинстве исследований методологической основой оценки экспортного потенциала служит теория гравитационных моделей, которая предполагает положительную связь торговли между двумя странами с уровнем предложения и спроса на продукцию и отрицательную - с ограничениями торговли в форме таможенных пошлин и изза географической удаленности. В ранних работах использование гравитационных моделей для прогнозирования двусторонней торговли, особенно в контексте интеграции Восток-Запад (Wang, Winters, 1992; Baldwin, 1994; Gros, Gonciarz, 1996), подвергалось фундаментальной критике из-за больших отклонений фактических данных от прогнозируемых. Так, Эггер утверждает, что значительная погрешность прогнозов указывает, скорее, на неправильную спецификацию модели, чем на неиспользованную возможность, и выступает за вневыборочные оценки, когда модель соответствует эталонной группе стран (Egger, 2002).

* Телеш Ирина Леонидовна (teleshira@mail.ru), кандидат экономических наук, НИЭИ Министерства экономики Республики Беларусь (г. Минск, Беларусь);

Баханцева Ирина Владимировна, НИЭИ Министерства экономики Республики Беларусь (г. Минск, Беларусь);

Русаков Ренат Александрович, НИЭИ Министерства экономики Республики Беларусь (г. Минск, Беларусь). 
Некоторые авторы применяют гравитационные модели для определения отраслевых торговых потенциалов отдельных стран. В одних работах оценка потенциалов отраслевой торговли производится на основе характеристик стран, что достаточно спорно с точки зрения специализации экономик (Melchior, Zheng, Johnsen, 2009; Shepotylo, 2009). Другие исследователи предполагают, что без отраслевой разбивки макроинформации результаты будут неточными (Fontagné, Pajot, Pateels, 2002; Helmers, Pasteels, 2006). В то же время данные о производстве и потреблении на уровне отдельного продукта часто недоступны и в современной статистической отчетности сложно сопоставимы, что, в свою очередь, может создать проблемы в процессе моделирования.

В последние годы в работах по теории гравитации появились новые методы оценки в выборке ${ }^{1}$. Однако межстрановые и межотраслевые спецификации, ввиду внедрения огромного числа коэффициентов, остаются исключительно требовательными с точки зрения трудовых затрат и вычислительных ресурсов. Кроме того, недостатком спецификаций с фиксированными эффектами - страна-продукт, товар-рынок и страна-рынок - является непрозрачность источника потенциального объема экспорта, что осложняет использование полученных результатов в определении внешнеторговой политики органами госуправления и другими заинтересованными лицами. Следовательно, для оценки экспортного потенциала на основе подробных данных на уровне продукта требуется другой, более практичный подход. Таковым может служить подход, разработанный исследователями Центра международной торговли (ITC) и используемый для оценки потенциала экспорта товаров. Он адаптирован авторами с учетом специфики торговли услугами.

В основу оценки экспортного потенциала отдельных видов продукции на целевой рынок, применяемой ITC, положена структурная модель, которая определяет потенци-

${ }^{1}$ Head K., Mayer T. 2014. Gravity Equations: Workhorse, Toolkit, and Cookbook. Handbook of International Economics. Vol. 4. Elsevier. PP. 131-195. альные доли продукции в объемах спроса и предложения и затем обращает их в потенциальные объемы, используя данные о перспективах взаимной торговли (Decreux, Spies, 2016). Некоторый разрыв между тем, что страны поставляют, и тем, что могут поставлять с учетом информации о регулировании целевого рынка, трудностях в торговле либо о потребительских запросах, и составляет определяемый потенциал. Фактически, неиспользуемый потенциал представляет собой краткосрочный прогноз возможностей для наращивания экспорта.

Теоретической основой оценки экспортного потенциала выступает гравитационная модель, применяемая на уровне отдельного товара или услуги. Начальной точкой является предположение о том, что взаимная торговля в мире может быть описана как комбинация:

$$
v_{i j k}=\alpha_{i k} \cdot \beta_{i j} \cdot \gamma_{j k}
$$

где $v_{i j k}$ описывает экспорт из страны $i$ продукта (товара или услуги) $k$ на рынок $j$;

$\alpha_{i k}-$ возможности $i$-й страны экспортировать продукт $k$;

$\gamma_{j k}-$ спрос $j$-го рынка на продукт $k$;
$\beta_{i j}-$ условия торговли (легкость или доступность экспорта какого-то продукта из $i$-й страны на рынок $j$ ).

Сторона предложения основывается на динамической версии рыночной доли, учитывающей такой фактор, как торговый баланс вида услуг. Сальдо внешней торговли отражает эффективность оказания услуг. Предполагается, что страна, которая экспортирует меньше услуг, чем импортирует, вряд ли будет иметь сильный экспортный потенциал для этого вида услуг.

В целом темп роста предложения представляет собой индекс опережения (или запаздывания) экспорта Беларуси относительно мирового экспорта данного вида услуг, скорректированного с учетом торгового баланса:

$$
\text { Iexp_ } \mathrm{TM}_{\mathrm{Pb}, k}=\frac{I_{\text {Эксп_Рв }, k}}{I_{\text {Эксп_мир }, k}} \cdot I_{\mathrm{TБ} \_ \text {РБ, }, k},
$$


где I $\exp _{-} \mathrm{TM}_{\mathrm{PБ}, k}$ - темп роста предложения Республики Беларусь $k$-го вида услуг;

$I_{\text {Эксп_рв }, k}$ - темп роста экспорта Республики Беларусь $k$-го вида услуг;

$I_{\text {Эксп_мир, } k}-$ темп роста мирового экспорта $k$-го вида услуг;

$I_{\text {ТБ_РБ, } k}$ - корректирующий индекс торгового баланса $k$-го вида услуг, который равен 1 при профиците и ниже 1 - при дефиците торговли.

Темпы роста рассчитываются как среднее за ряд последних лет (не менее 3 лет для краткосрочного прогноза).

Условия спроса рассматриваются как ожидаемый объем импорта целевого рынка определенного вида услуг. В качестве прогнозного темпа роста импорта принимается средний, рассчитанный за ряд последних лет.

Условия торговли между странами зависят от множества политико-экономических факторов. В случае с товарами доступность рынка описывается индикаторами различий в преференциях на целевом рынке, а также преимуществом в расстоянии от экспортера к потребителю.

Однако в торговле услугами тарифные барьеры и, соответственно, преимущества в них отсутствуют. Кроме того, развитие технологий, глобальная цифровизация привели к переходу многих видов услуг в виртуальную сферу, снижению потребности в физическом перемещении лиц за рубеж для потребления или предоставления услуг. Большинство видов услуг, таких как компьютерные, финансовые, страховые и др., не зависят от расстояния между странами, которое приходится учитывать при торговле товарами. Фактор расстояния может оказывать влияние на отдельные виды услуг, тесно связанные с трансграничным перемещением благ и физических лиц.

Исходя из вышеизложенного, экспортный потенциал $k$-го вида услуг, оказываемых организациями Республики Беларусь на целевом рынке, может быть определен следующим образом:

$$
\begin{aligned}
\mathrm{EP}_{\mathrm{PБ}_{\mathrm{TM}}, k}= & \operatorname{Exp}_{\mathrm{PБ}, k} \cdot \overline{I_{\text {имп }-\mathrm{TM}, k}} . \\
& \cdot \operatorname{Iexp}_{-} \mathrm{TM}_{\mathrm{PБ}, k} \cdot D_{\mathrm{TM} \_ \text {РБ }},
\end{aligned}
$$

где $\mathrm{EP}_{\mathrm{PБ}_{\mathrm{TM}}, k}-$ экспортный потенциал $k$-го вида услуг, оказываемых организациями на целевом рынке;

$$
\operatorname{Exp}_{\mathrm{PБ}, k} \text { - объем экспорта } k \text {-го вида }
$$
услуг, оказываемых организациями на целевом рынке в отчетном периоде;

Iexp_ $\mathrm{TM}_{\mathrm{PБ}, k}$ - темп роста предложения $k$-го вида услуг;

$\overline{I_{\text {имп-тм }, k}}-$ темп роста импорта целевым рынком $k$-го вида услуг;

$D_{\text {Tм_Рь }}-$ корректирующий индекс расстояния для $k$-го вида услуг, который учитывается экспертно для услуг, связанных с трансграничной деятельностью и потреблением за рубежом (например, услуги по обработке материальных ресурсов и ремонту оборудования), и равен 1 для прочих видов услуг.

Следует отметить, что экспортный потенциал $k$-го вида услуг Республики Беларусь на целевом рынке, рассчитанный на основе (3), отражает прогнозный объем для наращивания экспорта при сложившемся уровне нетарифных барьеров. В силу специфики и сложности рынков услуг либерализация международной торговли здесь происходит значительно медленнее, чем в торговле товарами, издержки входа на рынки услуг намного выше. Поэтому страны заключают преференциальные соглашения в торговле услугами, которые, при прочих равных условиях, создают критически значимые преимущества для стран-участниц по сравнению с третьими странами.

Количественное измерение уровня ограничений на рынках отдельных услуг дает возможность оценить вероятные объемы торговли при отсутствии барьеров в разных отраслях и сопоставить их с наблюдаемыми значениями этого показателя. Вместе с тем методология оценки ограничений в торговле услугами также остается актуальным предметом исследования в международной экономике.

В современной экономической литературе разработаны способы оценки барьеров для торговли услугами, которые включают количественные, частотные и ценовые типы измерения (McGuire, 2008). Хотя 
в работах, базирующихся на данном подходе, имеются определенные недостатки (оценки основываются на последних доступных данных; покрывается небольшой временной период, не отражающий долгосрочные тенденции в либерализации международной торговли), они получили широкое признание, поскольку формируют более адекватное представление о барьерах в торговле услугами.

При измерении уровня ограничений в торговле услугами качественная информация о конкретных барьерах преобразуется в сопоставимые количественные данные. Этот процесс разделен на два этапа.

На первом этапе производятся сбор и классификация информации об ограничениях. Для этого используется ряд источников, включая не только перечни обязательств в рамках ГАТС, но и отчеты правительств, исследования международных организаций (ВТО, АТЭС, ОЭСР, аналитической службы Economist Intelligence Unit). Таким образом создается более репрезентативная база данных об ограничениях в сфере услуг.

Затем следует расчет комплексного количественного показателя. Наиболее широко применяемым в настоящее время является Индекс ограничений торговли услугами (Services Trade Restrictiveness Index - STRI), разработанный экспертами Всемирного банка. Индекс составляется на основе базы данных по ограничениям в торговле услугами, аккумулирующей сведения о нормах регулирования в 22 секторах (компьютерные, строительные, финансовые, телекоммуникационные, транспортные, дистрибьюторские и др.) по трем способам поставки (трансграничная поставка, коммерческое присутствие и перемещение физических лиц). В настоящее время она включает 40 стран, 34 страны - члена ОЭСР, а также Бразилию, Китайскую Народную Республику, Индию, Индонезию, Российскую Федерацию и Южную Африку.

Меры регулирования сгруппированы по пяти сферам: рынок;

ограничения на вход иностранцев на

ограничения на передвижение людей; другие дискриминационные меры; барьеры для конкуренции; прозрачность регулирования.

Индекс STRI использует бинарную систему оценки и взвешивания. Отдельным мерам регулирования присваивается оценка 0 (не ограничивающая) или 1 (ограничительная). В рамках каждой из пяти сфер регулирования субиндексы являются равновесными. Общий индекс STRI по сектору услуг рассчитывается как средневзвешенный, где в качестве весов используются экспертные оценки относительной важности сфер регулирования (Grosso, Gonzales, Miroudot, Nordas, Rouzet, Ueno, 2015).

Однако не все меры в базе данных получают двоичную оценку: многие связаны между собой, а некоторые явно более важны, чем другие. В этом случае ограничениям присваиваются баллы в зависимости от их строгости: чем жестче ограничение, тем выше приписываемый балл. Используемая шкала варьируется от 0 до 100 с интервалом в 25 пунктов. Большей открытости рынка соответствуют более низкие значения индекса. После того как каждый вид барьеров оценивается в отдельности, вырабатывается агрегированный STRI по сектору услуг как средневзвешенный в зависимости от влияния того или иного барьера на рынок.

Описанный тип оценки ограничений торговли услугами часто дополняется методами для измерения эффекта на торговлю услугами. Подобное сочетание востребовано, поскольку выявление самих барьеров не способно охарактеризовать их экономическое значение для определения цены и объемов производства и потребления, а также масштабов международной торговли. Кроме того, оно не дает представления о последствиях продления или снятия существующих ограничений. Выделяют несколько способов дальнейшего измерения эффекта от сохранения барьеров в сфере услуг, одним из которых является преобразование индекса ограничений торговли услугами в тарифный эквивалент. Именно этот подход использован в данной работе.

Как отмечалось выше, для измерения степени строгости ограничений на торговлю услугами ежегодно разрабатывается индекс $S T R I_{\text {тм_k }}$, преобразующий качественную информацию о барьерах в сопоставимые коли- 
чественные данные. Индекс разрабатывается по 22 секторам услуг, его значение изменяется от 0 до 1, причем для более открытого рынка оно стремится к нулю. Для укрупненных видов услуг индекс ограничений можно рассчитать как средневзвешенное индексов секторов, образующих данный вид услуги, где в качестве весов использовать долю сектора в объеме импорта вида услуг в отчетном периоде.

Для удобства и сопоставимости в расчетах будем применять величину $\left(1-S T R I_{\mathrm{TM} k}\right)$, которая имеет обратную интерпретацию: чем выше значение индекса, тем более доступным для экспортеров является целевой рынок.

Заключение соглашений о свободной торговле услугами между странами ведет к полному или частичному открытию целевого рынка, ликвидации нетарифных барьеров и ограничений на нем. В этом случае индекс строгости ограничений $S T R I_{\mathrm{TM}_{-} k}^{1}$ будет ниже, а в идеале - равен нулю. Тогда страна получает преимущества в торговле услугами на целевом рынке перед другими странами, которые можно измерить с помощью опережающего коэффициента:

$$
I_{\mathrm{PF} \_k}^{a d}=\frac{1-S T R I_{\mathrm{TM} \_k}^{1}}{1-S T R I_{\mathrm{TM}_{-} k}^{0}} .
$$

При полном открытии целевого рынка для $k$-го вида услуг индекс торговых преимуществ будет иметь вид:

$$
I_{\mathrm{P}_{\_} k}^{a d}=\frac{1}{1-S T R I_{\mathrm{TM}_{-} k}^{0}} .
$$

Исходя из этого экспортный потенциал $k$-го вида услуг, оказываемых организациями Республики Беларусь, на целевом рынке после подписания соглашения о свободной торговле услугами может быть определен следующим образом:

$$
\begin{aligned}
E P_{\mathrm{PE}_{\mathrm{TM}}, k} & =\operatorname{Exp}_{\mathrm{PБ}, k} \cdot \overline{I_{\text {имп_тм }, k}} . \\
& \cdot \operatorname{Iexp} \_T M_{\mathrm{PB}, k} \cdot D_{\mathrm{TM} \_\mathrm{Pb}} \cdot I_{\mathrm{PE} \_k}^{a d},
\end{aligned}
$$

где $E P_{\mathrm{PБ}_{\mathrm{TM}}, k}-$ экспортный потенциал $k$-го вида услуг, оказываемых организациями на целевом рынке;

$$
\operatorname{Exp}_{\mathrm{PБ}, k} \text { - объем экспорта } k \text {-го вида ус- }
$$
луг, оказываемых организациями на целевом рынке в отчетном периоде;

Iexp_ $\mathrm{TM}_{\mathrm{PБ}, k}$ - темп роста предложения $k$-го вида услуг;

$\overline{I_{\text {имп-тм }, k}}-$ темп роста импорта целевым рынком $k$-го вида услуг

$D_{\text {тм_Рв }}-$ корректирующий индекс расстояния для $k$-го вида услуг;

$I_{\mathrm{P5} k}^{a d}-$ индекс торговых преимуществ на целевом рынке для $k$-го вида услуг.

Оценка изменений объемов экспорта при условии либерализации и снятии торговых барьеров производилась с использованием доступных в базе статистики ОЭСР индексов STRI, соответствующих методологии платежного баланса (МПБ). Исключение составили услуги туризма, не имеющие аналога в базе STRI, уровень ограничения торговли для которых рассчитывался авторами в соответствии с методологией ОЭСР отдельно.

Расчет индекса производился, исходя из определения поездок по МПБ как товаров и услуг, приобретаемых нерезидентами во время пребывания на территории целевой стра$\mathrm{Hы}^{2}$, подразумевающего второй способ экспорта услуги по ГАТС - потребление за рубежом. Хотя индекс STRI сосредоточен на 1 , 3 и 4 способе экспорта услуг по ГАТС, т. е. оказании услуг на территории страны потребителя, коммерческое присутствие в сфере туризма на целевом рынке позволяет проводить более эффективную и независимую маркетинговую стратегию для привлечения туристов. Таким образом, учитывались эти три способа выхода на рынок.

В результате анализа практик ограничения импорта туристических услуг различными странами, в том числе Китаем, перечень барьеров для расчета индекса, наряду с ключевым набором, был дополнен барьерами, связанными с лицензированием деятельности агентств, а также отсутствующими в методологии ОЭСР барьерами, в частности:

2 Balance of Payments and International Investment Position Manual. 2009. URL: https://www.imf.org/external/ pubs/ft/bop/2007/pdf/bpm6.pdf 
- требования членства агентства, предлагающего туристические услуги, в национальных туристических организациях в стране происхождения;

- действие системы разрешений на выезд туристов за пределы страны;

• наличие персональных налогов и сборов на выездной туризм;

- преимущества для группового туризма по отношению к индивидуальному.

Веса для пяти сфер регулирования в рамках индекса были установлены экспертным методом, с учетом распределения весов для других видов услуг.

Таким образом, представленный подход к оценке экспортного потенциала позволяет определить дополнительные возможности в поставках отдельных видов услуг при заключении соглашений о либерализации торговли услугами между странами.

\section{Динамика показателей торговли услугами КНР}

Экономика Китая - вторая по величине в мире, по показателю ВВП уступающая только США. Кроме того, КНР - крупнейший в мире торговец товарами и услугами, крупнейший экспортер товаров и второй по величине импортер товаров и услуг.

Торговля услугами Китая стремительно растет: с 2011 по 2019 г. среднегодовой прирост составил 8,6\%, при этом экспорт рос в среднем на 5,3\% в год, а импорт - на $11,1 \%$. Начиная с 2014 г. по объемам торговли услугами Китай прочно занимает второе место в мире. В 2019 г. он достиг 783,9 млрд долл. США, из которых экспорт составил 283,2 млрд долл., а импорт - 500,7 млрд долл. США (рис. 1). Особенностью торговли услугами КНР является ее дефицит: на протяжении последних лет отрицательное сальдо составляет более 200 млрд долл. США. Таким образом, наблюдается рост спроса со стороны китайских потребителей услуг.

В 2019 г. дефицит торговли услугами Китая составил 217,5 млрд долл. США. Основной вклад в формирование отрицательного сальдо внесли туристические услуги (поездки) - 216,3 млрд долл. США, или $99,4 \%$ от общего дефицита по торговле услугами (рис. 2).
Вторым источником являются транспортные услуги, дефицит которых достиг 58,8 млрд долл. США. Также отрицательное сальдо отмечалось по плате за использование ИС, в торговле страховыми и пенсионными услугами, услугами в области образования, культуры, здравоохранения, спорта и др. Профицит ИКТ-услуг (телекоммуникационных, компьютерных и информационных услуг), строительных услуг и прочих деловых услуг составил 26,9 млрд, 18,7 млрд и 23,5 млрд долл. США соответственно.

Ожидается, что в ближайшие пять лет Китай импортирует товаров и услуг на сумму в 10 трлн долл. США, в том числе услуг до 2 трлн долл. В то же время доля импорта услуг из Беларуси в общем объеме импорта услуг Китая в 2019 г. составила всего лишь $0,06 \%$. Несмотря на рост совокупного экспорта услуг Республики Беларусь, динамика их экспорта в КНР в период 2016-2019 гг. сложилась отрицательной. Стоимостные объемы сократились на 25,4\% до 321 млн долл. США (292,3 млн долл. США - в материковый Китай), а доля Китая в экспорте услуг страны упала с 7,2 до $3,6 \%$ (рис. 3).

Причиной нисходящего тренда послужило уменьшение объема строительных услуг. С 2015 г. их экспорт сократился на 55,6\%, составив в 2019 г. 134,7 млн долл. США. Основная часть строительных услуг оказывается на территории Беларуси. Строительные организации, входящие в систему Минстройархитектуры, принимают участие в китайских инвестиционных проектах в Республике Беларусь по договорам субподряда с компаниями - резидентами КНР. Спад экспорта в этот период был связан с завершением работ по строительству инженерной инфраструктуры стартовой зоны Китайско-Белорусского индустриального парка (КБИП), а также окончанием строительства завода по производству легковых автомобилей «Белджи» в р-не д. Пересады Борисовского района.

Второе место в экспорте услуг в Китай занимают транспортные услуги, находящиеся в положительном тренде после падения в 2016 г. до 72,0 млн долл. США. По итогам 2019 г. объем их экспорта составил 78,8 млн долл. США с долей в 24,5\%.

Наибольший удельный вес приходится на услуги морского транспорта, в част- 


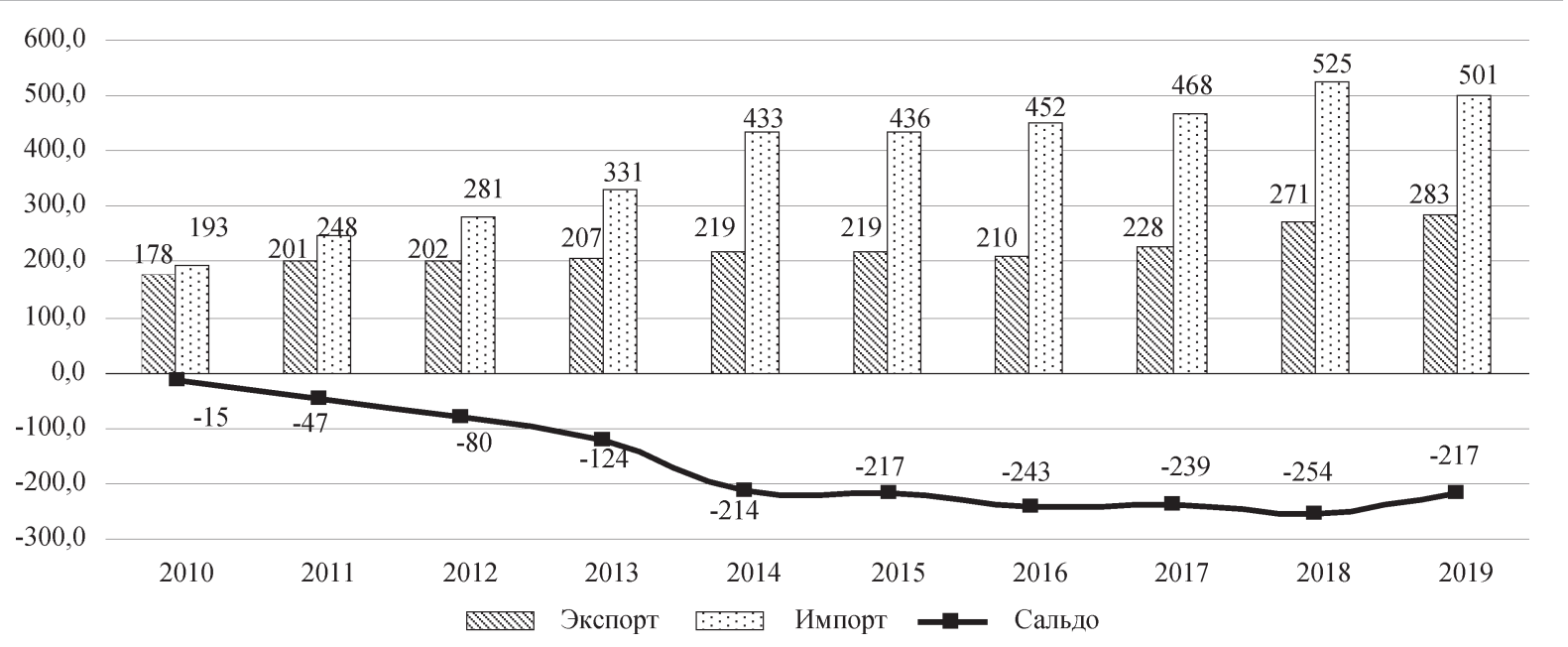

Рис. 1. Динамика торговли услугами Китая, млрд долл. США

Источник. URL: https://www.trademap.org/

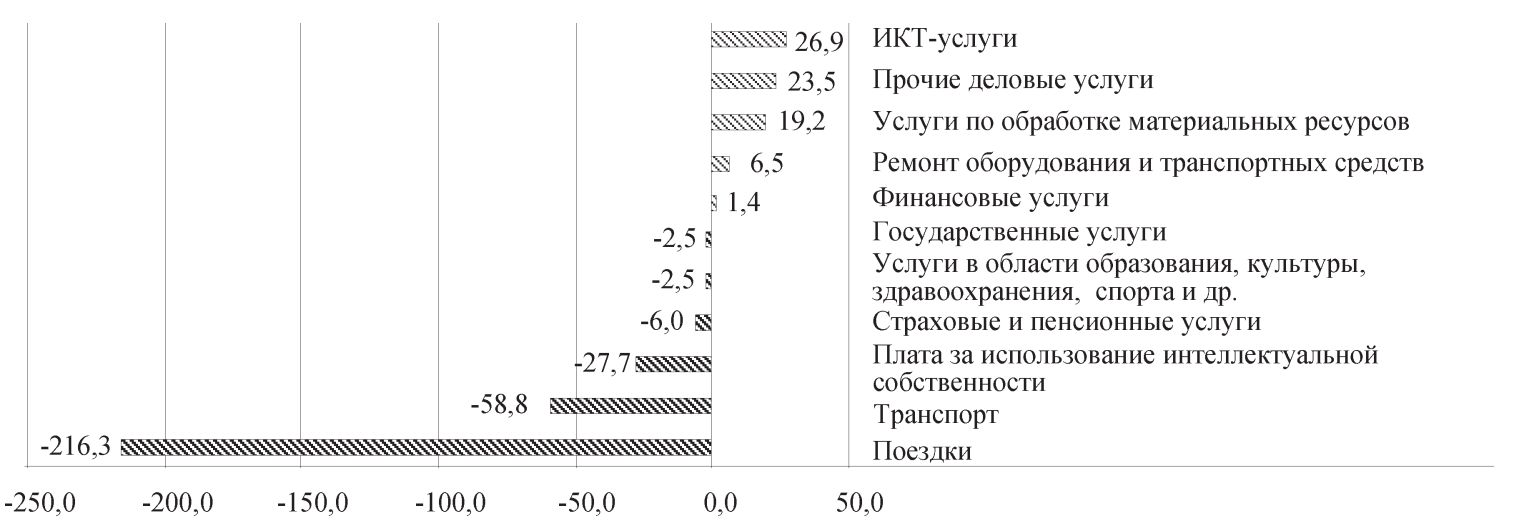

Рис. 2. Вклад различных видов услуг в формирование сальдо торговли услугами Китая в 2019 г., млрд долл. США

Источник. URL: https://www.trademap.org/

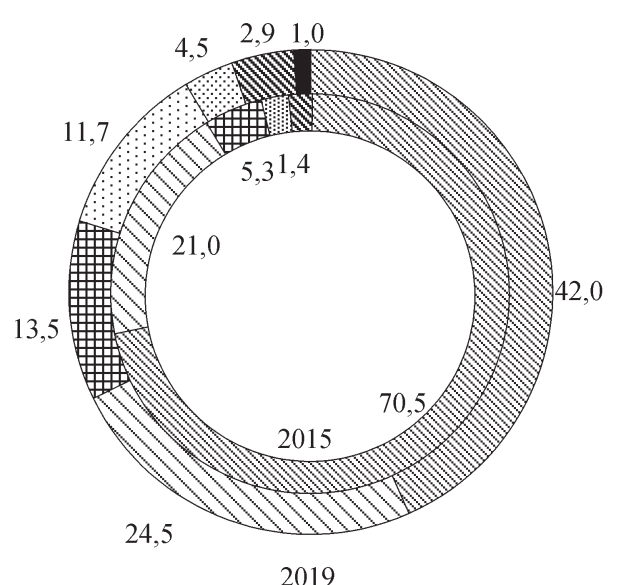

«.: Строительные

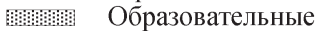

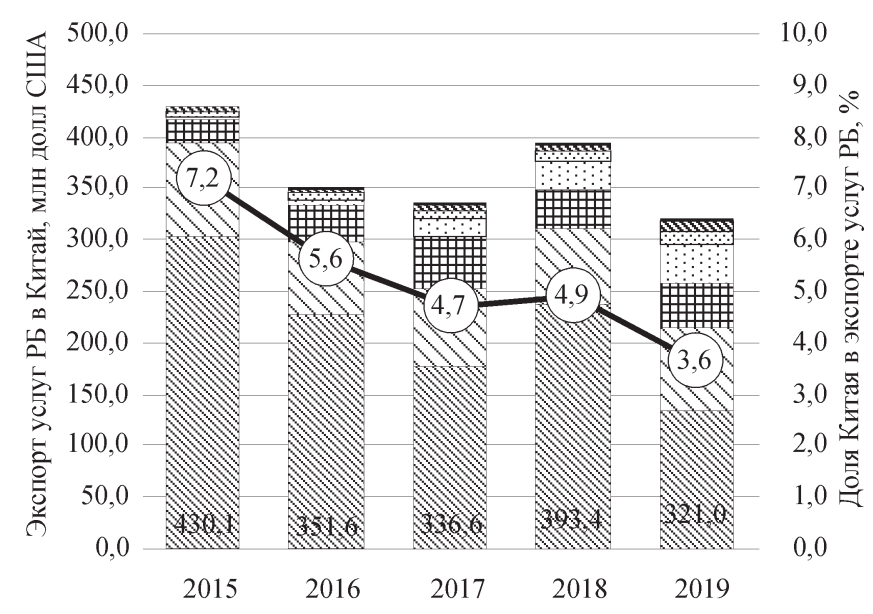

\. Транспортные

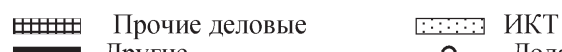

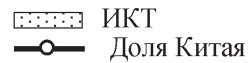

Рис. 3. Динамика экспорта услуг Беларуси в Китай (включая Гонконг, Тайвань и Макао)

Источник. URL: https://belstat.gov.by 
ности грузовые перевозки, включая аренду (фрахтование) морского транспорта с экипажем. Падение экспорта транспортных услуг в 2016 г. объясняется сокращением именно морских поставок - физических объемов экспорта калийных удобрений, формирующих основу морских отгрузок в Китай. С 2016 г. экспорт услуг морского транспорта постепенно возрастал, составив в 2019 г. 45,9 млн долл. США (58,3\% транспортных услуг).

Экспорт услуг автомобильного трансnорта, преимущественно грузового, в 20162019 гг. увеличился на 29,3\%, до 5,4 млн долл. США, что является наибольшим показателем экспорта в исследуемом периоде за исключением 2017 г.

Экспорт услуг железнодорожного трансnорта, в основном грузового, напротив, сократился на $34,9 \%$ по отношению к уровню 2015 г., составив в 2019 г. 1,5 млн долл. США. При этом следует учесть, что железнодорожные перевозки по маршруту Китай-ЕС, объемы которых значительно приросли в 2016-2018 гг., в объемах экспорта не отражены, поскольку обслуживаются дочерним предприятием Белорусской железной дороги - немецкой компанией «Белинтертранс-Германия».

С 2015 г. на 62,9\%, до 15,2 млн долл. США, вырос экспорт услуг воздушного mpaнспорта, в частности прочих услуг, в основном оказываемых в рамках служб аэропорта Минск-2 авиакомпании Air China. После резкого увеличения в 2016 г. крупную долю в составе транспортных услуг продолжают занимать почтовые и курьерские услуги. В 2019 г. она составила 10,7\% с объемом в 8,4 млн долл. США.

Большими объемами отличается экспорт прочих деловых услуг - 43,3 млн долл. США с долей в 13,5\%. Основную его часть формируют услуги по рекламе и маркетингу, в области науки, архитектуры, аренды оборудования и транспортных средств и пр. Такой состав и постепенный рост их экспорта также объясняется возрастанием числа китайских инвестиционных проектов на территории Беларуси.

К 2019 г. значительно вырос экспорт ИКТ-услуг - в 16,9 раза по сравнению с 2015 г., достигнув 37,5 млн долл. США.
Активный рост наблюдался в экспорте как компьютерных, так и телекоммуникационных услуг - до 23,2 и 13,6 млн долл. США соответственно. Основная доля ИКТ-услуг поставляется в Гонконг (91,4\% в 2019 г.), в то время как реализации высокого потенциала белорусской ИТ-индустрии в материковой части Китая препятствуют различные барьеры как культурного, так и технического характера.

С 2015 г. в 2,4 раза, до 14,5 млн долл. США, вырос экспорт образовательных услуг, почти полностью представленных очным обучением граждан Китая в Беларуси. Также за это время на 170\% увеличился экспорт туристических услуг в Китай. В 2019 г. он составил 9,2 млн долл. США. Удельный же вес сугубо гостиничных услуг сократился до 63,3\%, уступив место комплексным и прочим туристическим услугам. С 2012 г. Китай удерживает первое место в мире по потреблению туристических услуг за рубежом. В 2019 г. их объем составил 250,7 млрд долл. США.

Стремительный рост экспорта персональных услуг стал следствием регулярных мероприятий по повышению осведомленности и информированности граждан Китая об образовательных и рекреационных возможностях в Беларуси, проводимых в сотрудничестве с китайскими СМИ и интернет-площадками. Была достигнута договоренность с Air China о размещении в сетях компании и на рейсах информации о туристическом потенциале Беларуси.

В целом, белорусско-китайские отношения характеризуются высокой степенью доверия, открытости и взаимной поддержки на международной арене. Для развития экономических отношений, в том числе в сфере услуг, созданы благоприятные условия: подписаны и вступили в силу соглашения о сотрудничестве в экономической и финансовой сферах, о ключевых направлениях сотрудничества в области космоса, технологий интеллектуального мониторинга логистических потоков. Кроме того, договоры с КНР охватывают широкий спектр вопросов, касающихся защиты инвестиций, сотрудничества в области науки и технологий, искусства и культуры, образования, туризма, воздушного сообщения, здравоохранения, правовой помощи 
по гражданским и уголовным делам, защиты прав интеллектуальной собственности, безвизовых поездок и др.

Признавая потенциал обеих сторон по расширению в сфере торговли и развитию более тесных связей в области экономического сотрудничества, принимая во внимание совместные усилия по формированию современного «Шелкового пути», равно как и развитию Китайско-Белорусского индустриального парка «Великий камень», страны договорились обсудить подписание соглашения о торговле услугами и инвестициях с целью улучшения условий и расширения масштабов экономического сотрудничества двух стран. 30 апреля 2020 г. в Пекине сторонами был подписан Меморандум о взаимопонимании между Министерством коммерции Китайской Народной Республики и Министерством экономики Республики Беларусь о совместном исследовании целесообразности заключения соглашения о свободной торговле услугами и осуществлении инвестиций между Республикой Беларусь и Китайской Народной Республикой.

\section{Экспортный потенциал услуг Республики Беларусь на рынке КНР}

На основании описанных методических подходов была проведена оценка экспортного потенциала услуг Беларуси на рынке КНР (материкового Китая) в двух вариантах. В первом случае предполагалось сохранение текущих условий торговли и нетарифных ограничений для белорусских услуг на китайском рынке. В рамках второго варианта рассматривалось открытие рынка КНР для белорусских поставщиков после подписания двустороннего соглашения о свободной торговле услугами.

Согласно результатам расчетов по первому варианту, потенциальный объем экспорта услуг в КНР в краткосрочном периоде может достичь 316,5 млн долл. США (табл. 1). Потенциальный прирост экспорта услуг Беларуси на китайский рынок оценивается в среднем в 8-8,5\% ежегодно. Для сравнения, среднегодовой темп роста экспорта белорусских услуг в КНР за 20162019 гг. составлял всего лишь 91,1\%.

Как отмечалось выше, наибольший удельный вес в экспорте белорусских услуг в КНР занимают строительные услуги, однако ввиду понижающего тренда их динамики в последние годы дополнительных перспектив роста пока не предвидится.

В разрезе других видов услуг наибольший прирост экспортного потенциала отмечается у ИКТ-услуг (42,9\% ежегодно) и связанных с ними поступлений по плате за использование интеллектуальной собственности (46,5\% ежегодно), а также услуг в области образования, культуры, здравоохранения, спорта и др. (43,5\% ежегодно). Высокий прирост потенциала имеют услуги по ремонту оборудования и транс-

Таблица 1

Потенциальный объем экспорта наиболее востребованных на рынке Китая видов услуг Республики Беларусь в краткосрочном периоде

\begin{tabular}{|c|c|c|c|}
\hline \multirow[b]{2}{*}{ Вид услуг } & \multirow{2}{*}{$\begin{array}{c}\text { Экспорт } \\
\text { Беларуси в КНР, } \\
2019 \text { г., тыс. } \\
\text { долл. США }\end{array}$} & \multicolumn{2}{|c|}{ Потенциальный экспорт } \\
\hline & & $\begin{array}{l}\text { тыс. долл. } \\
\text { США }\end{array}$ & $\begin{array}{c}\text { Доля в общем } \\
\text { объеме прироста, } \\
\%\end{array}$ \\
\hline Всего & 292300,0 & 316516,0 & 100,0 \\
\hline $\begin{array}{l}\text { Из них: } \\
\text { транспортные }\end{array}$ & 84049,9 & 92445,7 & 34,7 \\
\hline $\begin{array}{l}\text { в области образования, культуры, } \\
\text { здравоохранения, спорта и др. }\end{array}$ & 16711,1 & 23984,9 & 30,0 \\
\hline прочие деловые услуги & 34035,7 & 40206,3 & 25,5 \\
\hline $\begin{array}{l}\text { телекоммуникационные, компьютерные } \\
\text { и информационные услуги }\end{array}$ & 3400,5 & 4859,6 & 6,0 \\
\hline ремонт оборудования и транспортных средств & 1705,8 & 2325,5 & 2,6 \\
\hline поездки & 9410,8 & 9542,0 & 0,5 \\
\hline $\begin{array}{l}\text { плата за использование интеллектуальной } \\
\text { собственности }\end{array}$ & 327,2 & 479,5 & 0,6 \\
\hline
\end{tabular}

Источник. Авторская разработка. 
портных средств (36,3\% ежегодно), прочие деловые услуги (18,1\% ежегодно) и транспортные (10\% ежегодно). Для поездок и финансовых услуг потенциальный прирост оценивается на уровне $0,9-1,4 \%$ ежегодно.

В абсолютном выражении на транспортные услуги будет приходиться порядка $35 \%$ дополнительного прироста экспорта. Значительных объемов могут достичь услуги в области образования, культуры, здравоохранения, спорта и др., а также прочие деловые услуги. В совокупности они составляют около 90\% потенциального прироста экспорта услуг Беларуси на китайский рынок. Что касается услуг по ремонту оборудования и транспортных средств, то их потенциал может быть реализован в случае увеличения числа совместных белорусско-китайских предприятий либо в результате расширения присутствия производителей из КНР в Беларуси (например, в индустриальном парке «Великий камень»).

Значительный импульс торговле услугами может придать заключение двустороннего соглашения о свободной торговле услугами между Республикой Беларусь и КНР. Китайский рынок считается достаточно закрытым. Исходя из индекса ограничений торговли услугами $\mathrm{STRI}^{3}$, наиболь-

${ }^{3}$ OECD. Stat: Services Trade Restrictiveness Index. URL: https://stats.oecd.org/Index.aspx? DataSetCode=STRI ший уровень протекционизма наблюдается в сфере ИКТ-услуг, почтовых и курьерских, юридических, консультационных услуг в области учета, аудита, бухгалтерского учета и налогообложения, по связям с общественностью, страховых услуг. В других секторах также действуют определенные ограничения.

Ликвидация барьеров и ограничений в торговле услугами между странами обеспечит дополнительный прирост объемов экспорта. В случае дальнейшей либерализации экспорт услуг может увеличиться почти в 1,5 раза до 436,3 млн долл. США (табл. 2). Как показывает практика, реализация всех договоренностей в рамках соглашения о ЗСТ занимает временной промежуток сроком до 3 лет. Следовательно, в среднесрочной перспективе среднегодовой прирост экспортного потенциала может составить порядка 14-14,5\%, что на 6 п. п. выше этого показателя при неизменных условиях торговли.

Согласно расчетам, после заключения соглашения о свободной торговле услугами ускоренный рост получают наиболее зарегулированные виды услуг. Так, объем услуг в области образования, культуры, здравоохранения, спорта и др. увеличится в 3,5 раза; ИКТ-услуг и роялти на ИС - в 2,1 раза; прочих деловых услуг - в 1,8 раза; поездок - в 1,66 раза. Транспортные услуги вырастут в

Таблица 2

Потенциальный объем экспорта наиболее востребованных на рынке Китая видов услуг Республики Беларусь в среднесрочной перспективе

\begin{tabular}{|c|c|c|c|}
\hline \multirow{2}{*}{ Вид услуг } & \multirow{2}{*}{$\begin{array}{c}\text { Экспорт } \\
\text { Беларуси в КНР, } \\
2019 \text { г. , тыс. } \\
\text { долл. США }\end{array}$} & \multicolumn{2}{|c|}{ Потенциальный экспорт } \\
\hline & & $\begin{array}{l}\text { тыс. долл. } \\
\text { США }\end{array}$ & $\begin{array}{c}\text { Доля в общем } \\
\text { объеме прироста, \% }\end{array}$ \\
\hline Всего & 292300,0 & 436301,4 & 100,0 \\
\hline $\begin{array}{l}\text { Из них: } \\
\text { транспортные }\end{array}$ & 84049,9 & 146492,1 & 43,4 \\
\hline $\begin{array}{l}\text { в области образования, культуры, } \\
\text { здравоохранения, спорта и др. }\end{array}$ & 16711,1 & 58499,9 & 29,0 \\
\hline прочие деловые услуги & 34035,7 & 62562,4 & 19,8 \\
\hline поездки & 9410,8 & 15642,7 & 4,3 \\
\hline $\begin{array}{l}\text { телекоммуникационные, компьютерные } \\
\text { и информационные }\end{array}$ & 3400,5 & 7109,8 & 2,6 \\
\hline $\begin{array}{l}\text { плата за использование интеллектуальной } \\
\text { собственности }\end{array}$ & 327,2 & 684,9 & 0,2 \\
\hline финансовые & 483,4 & 799,3 & 0,2 \\
\hline
\end{tabular}

Источник. Авторская разработка. 
1,74 раза и дадут наибольший прирост экспорта в абсолютном выражении в 62,4 млн долл. США, или 43\% от общего объема прироста. Появятся дополнительные возможности в сфере финансовых услуг: потенциал экспорта может увеличиться в 1,65 раза, достигнув уровня в 800 тыс. долл. США.

В оцениваемых условиях строительные услуги остаются аутсайдером. Однако изменить тенденции в этой сфере могут новые инвестиционные проекты, например строительство Национального футбольного стадиона и бассейна международного стандарта в Минске в рамках помощи КНР.

Что касается туристических услуг, обратной стороной высокой емкости и доступности рынка Китая стала широкая практика использования механизмов контроля выездного туристического потока в качестве элемента «мягкой силы» в международных отношениях. Кроме ограничений возможностей коммерческого присутствия (иностранные туристические агентства не имеют права предоставлять услуги выездного туризма), в Китае отмечается непрозрачность системы выдачи и отзыва лицензий для туристических агентств, равно как и Статуса проверенного направления (ADS) для стран. Имеют место временные разрешения на выезд, например в Тайвань, и требования по ограничению выездных туристических пакетов и программ, к примеру в Южную Корею в 2017 г. (Lim, Ferguson, Bishop, 2020). В итоге индекс ограничения торговли туристическими услугами в Китае сформировался на относительно высоком уровне в 0,476 п. (табл. 3).

Таблица 3

Расчетный индекс ограничений торговли туристических услуг в Китае

\begin{tabular}{|l|c|c|}
\hline \multicolumn{1}{|c|}{ Сфера регулирования } & Вес & Значение \\
\hline $\begin{array}{l}\text { Ограничения на вход } \\
\text { иностранцев на рынок }\end{array}$ & 0,245 & 0,152 \\
\hline $\begin{array}{l}\text { Ограничения на } \\
\text { передвижение людей }\end{array}$ & 0,156 & 0,072 \\
\hline $\begin{array}{l}\text { Другие дискриминационные } \\
\text { меры }\end{array}$ & 0,197 & 0,118 \\
\hline Барьеры для конкуренции & 0,195 & 0,049 \\
\hline $\begin{array}{l}\text { Прозрачность } \\
\text { регулирования }\end{array}$ & 0,207 & 0,085 \\
\hline \multicolumn{2}{|l}{ Итого } & 0,476 \\
\hline
\end{tabular}

Источник. Авторская разработка.
При отмене ограничений для доступа на китайский рынок белорусских туристических услуг их экспорт может увеличиться в 1,66 раза.

Таким образом, нарастить свое присутствие на рынке услуг Китая Республика Беларусь может за счет расширения объемов предоставления транспортных, телекоммуникационных, компьютерных и информационных, туристических, прочих деловых услуг, а также услуг в области образования, культуры, здравоохранения, спорта и др.

K сожалению, пандемия COVID-19 и связанные с нею ограничения по всему миру внесли существенные коррективы в развитие торговли услугами в 2020 г. Однако потенциал роста сохраняется. Полученные данные позволяют определить направления усиления и интенсификации взаимодействия Республики Беларусь и Китайской Народной Республики в сфере торговли услугами.

\section{СПИСОК ЛИТЕРАТУРЫ (REFERENCES)}

Baldwin R.E. 1994. Towards an Integrated Europe. London: Centre for Economic Policy Research. 234 p.

Decreux Y., Spies J. 2016. Export Potential Assessments: A methodology to identify export opportunities for developing countries. Seminars at ITC and WTO. URL: https://www. semanticscholar.org/paper/Export-PotentialAssessments-A-methodology-to-for-Decreux-Spies/ a2e0541260f9b922f534bd4448c0101c9a93816f

Egger P.H. 2002. An Econometric View of the Estimation of Gravity Models and the Calculation of Trade Potentials. The World Economy. Vol. 25. No 2. PP. 297-312. DOI: 10.1111/1467-9701.00432

Fontagné L., Pajot M., Pasteels J.-M. 2002. Potentiels de commerce entre économies hétérogènes: un petit mode d'emploi des modèles de gravité. Economie \& Prévision. No 1-2. PP. 115-139. DOI: 10.3406/ecop.2002.6369

Gros D., Gonciarz A. 1996. A note of the Trade Potential of Central and Eastern Europe. European Journal of Political Economy. Vol. 12. Iss. 4. PP. 709-721.

Grosso M.G., Gonzales F., Miroudot S., Nordas H.K., Rouzet D., Ueno A. 2015. Services 
Trade Restrictiveness Index (STRI): Scoring and Weighting Methodology. OECD Trade Policy Papers. No 177. DOI: $10.1787 / 5 j \mathrm{j} 7 \mathrm{n} 8$ wbtk9r-en

Helmers C., Pasteels J. 2006. Assessing Bilateral Trade Potential at the Commodity Level: An Operational Approach. International Trade Center Working Paper.

Lim D.J., Ferguson V.A., Bishop R. 2020. Chinese Outbound Tourism as an Instrument of Economic Statecraft. Journal of Contemporary China. Vol. 29. Iss. 126. PP. 916-933. DOI: 10.1080/ 10670564.2020.1744390

McGuire G. 2008. Measuring and Modelling Restrictions on Trade in Services: A Case of Asia-
Pacific Economic Cooperation Economies. Macao Regional Knowledge Hub Working Papers. No 13. 40 p.

Melchior A., Zheng J., Johnsen A. 2009. Trade barriers and export potential: Gravity estimates for Norway's exports. Oslo: NUPI. URL: https://www.regjeringen.no/globalassets/upload/ nhd/handelsavtaler/trade-barriers-and-exportpotential.pdf

Shepotylo O. 2009. Gravity with Zeros: Estimating Trade Potential of CIS countries. SSRN Electronic Journal. DOI: 10.2139/ssrn.1347997

Wang Z., Winters A. 1992. The Trading Potential of Eastern Europe. Journal of Economic Integration. Vol. 7. No 2. PP. 113-136.

\title{
ASSESSMENT OF THE SERVICES EXPORT POTENTIAL OF THE REPUBLIC OF BELARUS ON THE PRC MARKET
}

\author{
Irina Telesh ${ }^{1}$, Irina Bakhantseva ${ }^{1}$, Renat Rusakov ${ }^{1}$ \\ Author affiliation: ${ }^{1}$ The Economy Research Institute of the Ministry of Economy of the Republic \\ of Belarus (Minsk, Belarus). \\ Corresponding author: Irina Telesh (teleshira@mail.ru).
}

ABSTRACT. The article provides an assessment of a mid-term growth potential for the Republic of Belarus in services exports to the People's Republic of China. Various approaches to identify prospects are considered as well as its dynamics over 2015-2019. The analysis rests on a current methodological base including International trade center studies. Additionally export potential assessment is held given liberalization of trade relationships between parties and the improvement of non-tariff barriers to trade in service.

KEYWORDS: foreign trade, services exports, export potential, trade barriers.

JEL-code: F14, F17.

DOI: $10.46782 / 1818-4510-2021-1-118-129$

Received 25.02.2021 